\title{
Hoarseness of Voice: A Retrospective Study of 251 Cases
}

\author{
${ }^{1}$ Hansa Banjara, ${ }^{2}$ Varsha Mungutwar, ${ }^{3}$ Digvijay Singh, ${ }^{4}$ Anuj Gupta \\ ${ }^{1-4}$ Department of ENT and Head and Neck Surgery, Pt. Jawahar Lal Nehru Memorial Medical College, Raipur, Chhattisgarh, India
}

Correspondence: Digvijay Singh, Department of ENT and Head and Neck Surgery, Pt. Jawahar Lal Nehru Memorial Medical College, Raipur, Chhattisgarh, India, e-mail: drdiggi@yahoo.com

\section{ABSTRACT}

Aims: Hoarseness of voice is a common symptom in otolaryngological practice and it is the earliest manifestation of a large variety of conditions directly or indirectly affecting the larynx, ranging from benign to most malignant. This study was undertaken to find out clinical profile, predisposing factors and etiology of hoarseness of voice.

Methods: A retrospective cohort analysis was carried out in Department of ENT, Pt JNM Medical College, Raipur, in 251 cases of change in voice for 3 years duration. All cases were analyzed for detailed history and underwent pre- and postoperatively stroboscopic examination to reach the diagnosis.

Results: Total 251 cases with M:F ratio of 1.9:1 were analyzed. Patients age ranged from 11 to 80 years and majority of patients equally presented in 4th and 6 th decade. Nonvocal/nonprofessional group constituted as a single largest group (85.26\%). Smoking was commonest predisposing factor (44.22\%) followed by vocal abuse (30.28\%). Out of 251 cases, $83.67 \%$ cases were organic and $16.33 \%$ cases were functional in origin.

Keywords: Hoarseness, Voice, Etiology, Vocal professionals, Organic lesion, Functional lesion.

\section{INTRODUCTION}

The voice is the primary means of communication for humans both socially and in the work place. Hoarseness is the term used to describe a change in normal voice quality and it is invariably the earliest manifestation of a large variety of conditions directly or indirectly affecting the voice apparatus.

Jackson and Jackson (1930) feel that hoarseness is the most important symptom of laryngeal disease and it is only absent when the cords and the motor mechanism are entirely free from disease. ${ }^{1}$ However, it should be re-emphasized that hoarseness is not a disease in itself, but rather a symptom of disease or disturbance in the larynx or along the course of the laryngeal motor nerve. It is often the first and only signal of serious local or systemic disease (Von Leden, 1958). ${ }^{2}$ The disease ranges from totally benign to the most malignant, and therefore a varying degree of significance is attached to this.

\section{AIMS AND OBJECTIVES}

1. To analyze clinical profile of hoarseness.

2. To find out incidence of common etiological factors of hoarseness.

3. To find out association of common predisposing factors leading to hoarseness.

\section{MATERIALS AND METHODS}

This retrospective study was carried out in Department of ENT, Pt JNM Medical College and associated Dr BRAM Hospital,
Raipur, Chhattisgarh from June 2007 to September 2010 in a period of three years.

The proforma was designed based on objective of the study. As per proforma, detailed history, examinations, clinical and final diagnoses were noted. Each patient was examined by videostroboscopy pre- and postoperatively and, if required, diagnosis was confirmed by histopathological findings.

\section{OBSERVATIONS AND RESULTS}

\section{Incidence of Hoarseness of Voice}

A total of 55040 cases attended the ENT OPD (39014 new and 16026 old) from June 2007 to September 2010. Out of these, 251 patients presented with complaint of change in voice. The incidence of hoarseness among total OPD patients was $0.45 \%$ and incidence among new cases was $0.64 \%$.

\section{Age and Sex Distribution}

This is shown in Figure 1. Among 251 cases, 164 (65.34\%) were males and $87(34.66 \%)$ were females. Age ranged between 11 to 78 years. Male predominance was observed with male:female ratio of 1.89:1. Majority of patients were presented in 4th (22.31\%) and 6th decades (22.31\%) of life followed by 3rd decade (20.72\%). Male patient showed higher percentage (26.83\%) in 51 to 60 years age group while female patient showed higher percentage (33.33\%) in 31 to 40 years age group. 


\section{Profession}

Profession with sex distribution is shown in Figure 2. Largest group of patients were housewives (19.52\%), laborer/farmer (17.53\%), private job/businessman (15.94\%), student (7.97\%), teacher $(7.57 \%)$, retired person $(5.18 \%)$, and factory worker (3.98\%). Rests were politicians (2\%), army personnel (1.59\%), singer (1.59\%), and sportsman. In males largest group was of laborer/farmer class (23.78\%). In females, housewives (56.32\%) made largest group.

\section{Vocal Professionals}

This is according to classification by Koufman and Isaacson ${ }^{3}$ (Fig. 3):

1. Level I (the elite vocal performers) $-1.59 \%$

2. Level II (the professional voice users) $-3.59 \%$

3. Level III (nonvocal professionals) - $9.56 \%$

4. Level IV (nonvocal nonprofessionals) $-85.26 \%$.

\section{Presenting Complaints}

Total 296 complaints were noted from 251 patients (Table 1). Some patients had more than two complaints at the time of

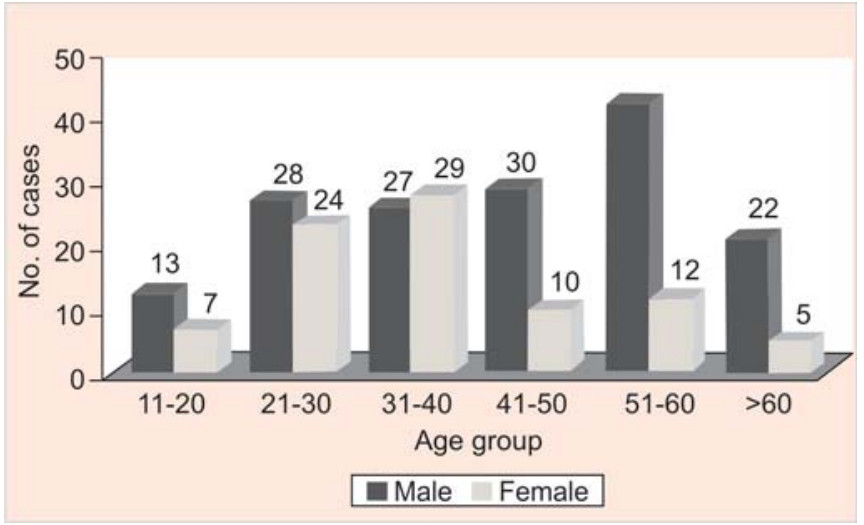

Fig. 1: Age and sex distribution in total 251 cases of hoarseness of voice

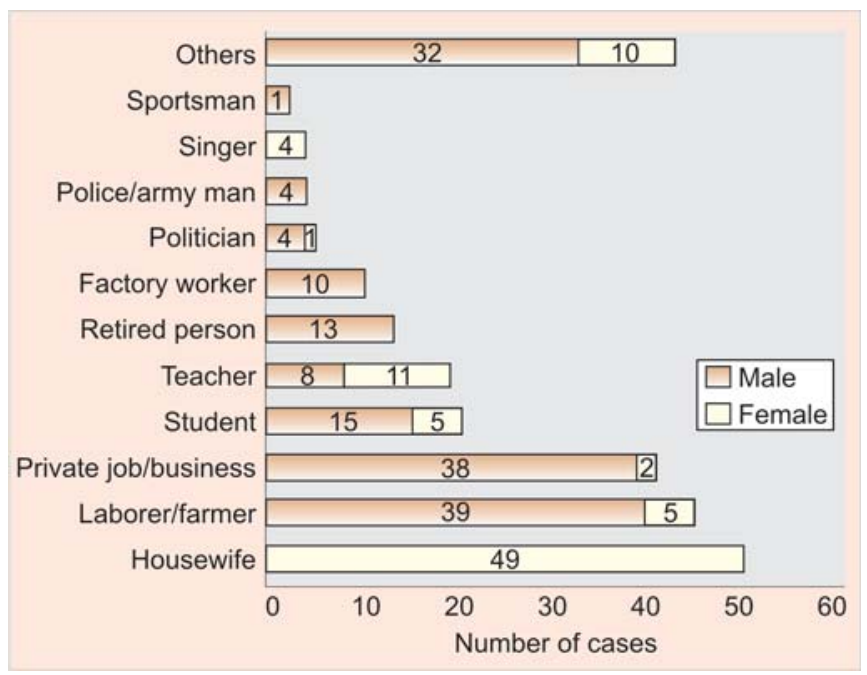

Fig. 2: Distribution of profession in 251 cases of hoarseness of voice

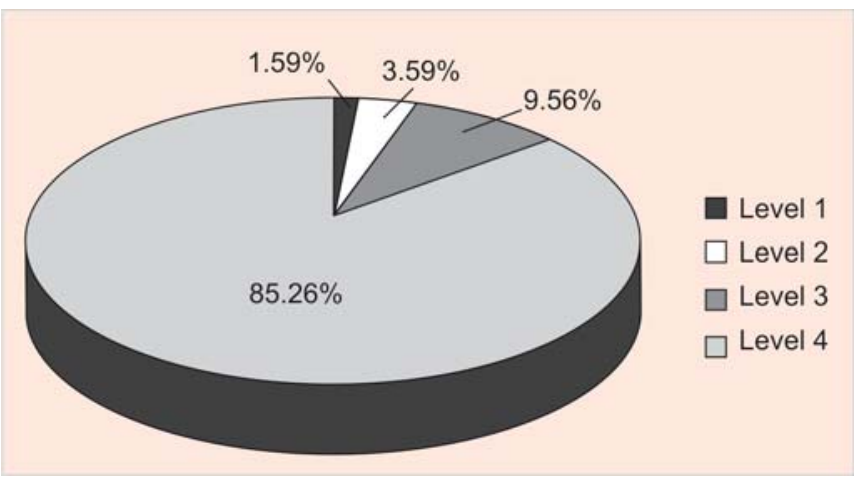

Fig. 3: Distributions of vocal professional level

examination. Change in voice/hoarseness was the common presenting symptom in 240 cases (95.61\%). Around 10 (3.98\%) cases presented with vocal fatigue and one case with aphonia. Other associated symptoms were dysphagia in 16 cases (6.37\%), foreign body throat sensation/irritation in 16 cases (6.37\%), neck swelling/secondaries in 6 cases (2.39\%) and dyspnea in 4 cases $(1.59 \%)$. Around 3 (1.2\%) cases presented with laryngeal trauma.

\section{Duration of Hoarseness}

Complaint with duration (month) is shown in Table 1. Duration of hoarseness ranged from 7 days to more than 5 years. Most of the presenting complaints (61.35\%) were seen within 3 months, $25.10 \%$ within 3 to 6 months and $10.76 \%$ within 6 to 12 months. $20.72 \%$ complaints were of more than 1 year duration.

\section{Etiology of Hoarseness of Voice}

In present study, almost all types of vocal pathologies were observed. Different vocal lesions with sex distribution and predisposing factors are shown in Table 2. Functional voice disorders were the largest group observed (16.33\%). In decreasing order other lesions were nodule (11.95\%), palsy (11.16\%), cancer (9.56\%), chronic laryngitis (9.56\%), cyst (5.58\%), edema (5.18\%), acute laryngitis (4.38\%), bowing (3.98\%), polyp (3.59\%), sulcus (2.79\%), and abductor palsy $(2.39 \%)$

\section{Predisposing Factors}

These are shown in Table 2. Smoking and vocal abuse were the predisposing factor in 43 and $31 \%$ cases of hoarseness respectively. Other factors in descending order were alcohol (29.48\%), tobacco/gutkha (29.48\%), and URI/septic foci(17.13\%). In more than one fourth cases (27.49\%) no predisposing factors were found, which mainly constitute change in voice with normal laryngeal findings (23 cases), palsy (11 cases), abductor palsy (4 cases), papilloma (3 cases) and sulcus (4 cases).

\section{DISCUSSION}

\section{Clinical Profile of Hoarseness}

The incidence of hoarseness among total OPD patients was $0.45 \%$ and incidence among new cases was $0.64 \%$. In a study, 


\begin{tabular}{|c|c|c|c|c|c|c|}
\hline \multirow[t]{2}{*}{ No. } & \multirow[t]{2}{*}{ Complaints } & \multicolumn{4}{|c|}{ Duration (months) } & \multirow[b]{2}{*}{ Totall(\%) } \\
\hline & & $<3$ & $3-6$ & $6-12$ & $>12$ & \\
\hline 1. & Change in voice & 117 & 52 & 24 & 47 & $240(95.61)$ \\
\hline 2. & Dysphagia & 14 & 2 & - & - & $16(6.37)$ \\
\hline 3. & $\mathrm{FB}$ sensation/irritation & 11 & 2 & 1 & 2 & $16(6.37)$ \\
\hline 4. & Vocal fatigue & 3 & 5 & 2 & - & $10(3.98)$ \\
\hline 5. & Neck swelling & 2 & 1 & - & 3 & $6(2.39)$ \\
\hline 6. & Dyspnea & 3 & 1 & - & - & $4(1.59)$ \\
\hline 7. & Trauma/injury larynx & 3 & - & - & - & $3(1.20)$ \\
\hline 8. & Aphonia & 1 & - & - & - & $1(0.40)$ \\
\hline & Total & 154 (61.35\%) & $63(25.10 \%)$ & $27(10.76 \%)$ & $52(20.72 \%)$ & 296 \\
\hline
\end{tabular}

Table 2: Etiology and sex distribution with predisposing factors

\begin{tabular}{|c|c|c|c|c|c|c|c|c|c|}
\hline \multirow[t]{2}{*}{ Diagnosis } & \multirow[t]{2}{*}{ No. of cases (\%) } & \multicolumn{2}{|c|}{ Sex } & \multirow[b]{2}{*}{ Smoking } & \multirow[b]{2}{*}{ Tobacco/gutkha } & \multicolumn{2}{|c|}{ Predisposing factor } & \multirow[b]{2}{*}{$\begin{array}{l}\text { Uri/septic } \\
\text { foci }\end{array}$} & \multirow[b]{2}{*}{ No. of factors } \\
\hline & & $M$ & $F$ & & & Alcohol & $\begin{array}{l}\text { Vocal } \\
\text { abuse }\end{array}$ & & \\
\hline Functional lesion & 41 (16.33) & 28 & 13 & 5 & 2 & 2 & 6 & 3 & 23 \\
\hline Vocal nodule & 30 (1 1.95) & 11 & 19 & 9 & 9 & 9 & 27 & 7 & 0 \\
\hline Vocal palsy & $28(11.16)$ & 20 & 8 & 15 & 9 & 10 & - & 2 & 11 \\
\hline Cancer & $24(9.56)$ & 19 & 5 & 19 & 24 & 19 & - & 2 & 0 \\
\hline Vocal cyst & $14(5.58)$ & 9 & 5 & 5 & 2 & 5 & 12 & 4 & 2 \\
\hline Vocal edema & $13(5.18)$ & 9 & 4 & 9 & 2 & 2 & 1 & 2 & 2 \\
\hline Acute laryngitis & $11(4.38)$ & 9 & 2 & 5 & 3 & 3 & 2 & 5 & 2 \\
\hline Bowing & $10(3.98)$ & 7 & 3 & 6 & 4 & 4 & 3 & - & 3 \\
\hline Vocal polyp & 9 (3.59) & 5 & 4 & 4 & 2 & 1 & 7 & 2 & 1 \\
\hline Sulcus vocalis & 7 (2.79) & 1 & 6 & 1 & 1 & 1 & 3 & 2 & 4 \\
\hline Abductor palsy & $6(2.39)$ & 5 & 1 & 2 & 1 & 1 & - & - & 4 \\
\hline Papilloma & $4(1.59)$ & 2 & 2 & 1 & - & - & - & 2 & 3 \\
\hline Keratosis & $4(1.59)$ & 2 & 2 & 2 & 1 & 1 & - & - & 2 \\
\hline Leukoplakia & $3(1.20)$ & 3 & 0 & 3 & 3 & 3 & 2 & 1 & 0 \\
\hline Scarring & $3(1.20)$ & 3 & 0 & 2 & 1 & 2 & 2 & 1 & 0 \\
\hline Injury/trauma & $3(1.20)$ & 3 & 0 & - & - & 1 & - & - & 2 \\
\hline Ulcer & $3(1.20)$ & 2 & 1 & 1 & - & - & - & 1 & 1 \\
\hline Reflux laryngitis & $2(0.80)$ & 1 & 1 & 1 & 1 & 1 & 1 & 2 & 0 \\
\hline Vocal hemorrhage & $2(0.80)$ & 1 & 1 & - & - & - & 1 & - & 1 \\
\hline Tuberculosis & $2(0.80)$ & 0 & 2 & - & - & - & - & - & 2 \\
\hline Rhinosporodiosis & $1(0.40)$ & 1 & 0 & - & - & 1 & - & - & 0 \\
\hline Granuloma & $1(0.40)$ & 1 & 0 & 1 & - & - & - & - & 0 \\
\hline Reinke's edema & $1(0.40)$ & 1 & 0 & 1 & - & - & 1 & - & 0 \\
\hline Hemangioma & $1(0.40)$ & 1 & 0 & - & - & - & 1 & - & 0 \\
\hline Total & 251 & $\begin{array}{c}164 \\
(65.34 \%)\end{array}$ & $\begin{array}{c}87 \\
(34.66 \%)\end{array}$ & $\begin{array}{l}108 \\
(43 \%)\end{array}$ & $\begin{array}{c}74 \\
(29.48 \%)\end{array}$ & $\begin{array}{c}74 \\
(29.48 \%)\end{array}$ & $\begin{array}{l}78 \\
(31 \%)\end{array}$ & $\begin{array}{c}43 \\
(17.13 \%)\end{array}$ & $\begin{array}{c}69 \\
(27.49 \%)\end{array}$ \\
\hline
\end{tabular}

the incidence of hoarseness among total OPD patients and among new cases was 0.32 and $0.66 \%$ respectively. ${ }^{4}$ In another study incidence of hoarseness was $0.3 \% .^{5}$

In the available literatures, incidence of hoarseness among patients attending ENT OPD could not be found. This problem has also been encountered by some author. ${ }^{4,6}$ Parik (1991) also comments - "It is strange that hoarseness as a subject has not attracted the attention of many workers". 7

A male:female ratio of 1.89:1 with male predominance was observed in this study. Our finding is exactly in confirmation with that of other studies, which also showed male predominance. ${ }^{4,6-9}$

In present study, majority of patients were seen in age group of 31 to 40 years (22.31\%) and 51 to 60 years (22.31\%) followed by 3rd decade (20.72\%). Baitha et al (2002) also found majority of patients (28.18\%) in the age group of 31 to 40 years. ${ }^{4}$ Batra et al (2004) found largest group comprising $25 \%$ in 31 to 40 years age group. ${ }^{9}$ Both the findings are similar to our study. Ghosh et al (2001) found majority of patients (28\%) in the age group of 21 to 30 years. ${ }^{10}$

Herrington-Hall et al (1988) stated that taking the variable of age into account, it is clear that laryngeal pathologies occur most frequently in the older age group because carcinoma and vocal fold paralysis being the most commonly found causes of vocal dysfunction in the elderly. Females presented with laryngeal pathologies at a slightly younger age. They found laryngeal pathologies mostly in the older age groups, $57 \%$ of the patients over 45 years of age with $22.4 \%$ over age 64 years. ${ }^{11}$ 
This statement supports our finding that majority of cases (22.31\%) were presenting in 51 to 60 years age group. Majority of males (26.83\%) were presented in age group 51 to 60 years whereas majority of female (60\%) presented in 21 to 40 years age group.

Present study included the entire patient with change in voice along with vocal fatigue and aphonia. Other authors also mentioned the hoarseness as major complaint. Other associated symptoms were dyspnea, dysphagia, throat pain and foreign body sensation. ${ }^{4,7}$ Typical laryngopharyngeal reflux symptoms include dysphonia, globus pharyngeus, mild dysphagia, chronic cough, excessive throat mucus and nonproductive chronic throat clearing. ${ }^{12}$

Duration of hoarseness ranged from 7 days to more than 5 years. Most of the presenting complaints (61.35\%) were seen within 3 months, $25.1 \%$ within 3 to 6 months and $10.76 \%$ within 6 to 12 months. $20.72 \%$ complaints were of more than 1 year duration. Batra et al (2004) found 59\% patients within first five months of appearance of symptoms and $86 \%$ of patients were found to present within first year of appearance of symptoms. ${ }^{9}$ Baitha et al (2002) noted duration range from 1 day to 5 years and $50 \%$ patients had duration of hoarseness in month. ${ }^{4}$ Chopra and Kapoor (1997) have noted 68.65\% patients with duration of hoarseness of less than one year. ${ }^{13}$

\section{Vocal Professionals}

Voice use demands and vocal technique are central to the trauma and pathogenesis of vocal fold masses in vocal professionals. In our study, majority of cases (19.52\%) were housewives followed by $17.53 \%$ of laborer/farmer. In males majority of cases were laborers. In study by Ghosh et al (2001) majority of patients (29\%) were housewives. ${ }^{10}$ Laborer constituted the single largest group of patients (36.36\%) followed by housewives (21.81\%) in another study. ${ }^{4}$

Fritzell (1996) and Titze et al (1997) reported that professionals with the highest risk of having voice problems are singers, followed by consultants, teachers, lawyers, pastors, telemarketers, salespersons, and health professionals. An important point is that a professional voice user will seek medical help only if he or she is aware of its importance among other things. ${ }^{14,15}$ Smith et al (1997) concluded that teaching was a high-risk occupation for voice disorders with the possibility of significant work-related consequences. ${ }^{16}$

Boominathan et al (2008) surveyed 400 voice professionals (100 singers, 100 teachers, 100 politicians and 100 vendors) in India and reported that $86 \%$ of politicians and $74 \%$ of vendors had voice problems. Politicians and vendors had the highest point prevalence of voice problems when compared with that of teachers and singers. $59 \%$ of singers and $49 \%$ of teachers also reported to have voice problems. ${ }^{17}$

When Herrington-Hall et al (1988) looked at the influence of occupation; they found that the presence of laryngeal pathologies tend to reflect both the amount of voice use and the conditions under which voice was used (including noise and stress). Of the 73 occupations identified in the study, the most frequent were retired persons, homemakers, executives/ managers, teachers, students, secretaries, singers, and nurses. The retired groups are normally the elderly group, and they seen that laryngeal problems are more common in the aging population, although the rarity of vocal nodules suggests that vocal abuse is seldom a cause of voice disorder in the elderly. ${ }^{11}$

Koufman and Isaacson (1991) evolved a classification of vocal professionals based on their voice use and risk. ${ }^{3}$

1. Level I (elite vocal performers): Included sophisticated voice users like the singers and actors, where even a slight vocal difficulty causes serious consequences to them and their careers.

2. Level II (professional voice users): For whom even moderate vocal difficulty would hamper adequate job performance. Clergymen, lecturers, teachers, politicians, public speakers, and telephone operators would classify in this level of voice users.

3. Level III (nonvocal professionals): It includes teachers and lawyers. They can perform their jobs with slight or moderate voice problems; only severe dysphonia endangers adequate job performance.

4. Level IV (nonvocal/nonprofessionals): Include laborers, homemakers and clerk. These are the persons who are not impeded from doing their work when they experience any kind of dysphonia.

In present study, according to this classification, we found $1.59 \%$ elite vocal performers, 3.59\% professional voice users, 9.56\% nonvocal professionals and $85.26 \%$ nonvocal/ nonprofessionals. Batra et al (2004) found $52.9 \%$ of patients in level IV of vocal usage, i.e. nonvocal/nonprofessional. The distribution in the remaining three levels was equal to $15.7 \%$ each. ${ }^{9}$

\section{Predisposing Factors}

In our study, commonest habit noted was smoking in 108 cases (43\%) followed by vocal abuse (31\%), alcohol intake (29.48\%) and tobacco/gutkha chewing (29.48\%). Upper respiratory infection and septic foci were least common factors found in $17.13 \%$ cases. In $27.49 \%$ cases no predisposing factors were observed. In a study vocal abuse was noted in $72 \%$ of cases. ${ }^{10}$ In another study smoking was noted in $25.45 \%$ of cases, chewing tobacco preparation was noted in $17.27 \%$ and alcohol in $12.72 \% .{ }^{4}$ Another study showed vocal abuse in $56 \%$ cases. $^{7}$

In present study, vocal abuse was main predisposing factor in vocal nodules (90\%), cyst (85\%) and polyp (77\%). Smoking and tobacco/gutkha chewing together constitute major predisposing factor in malignancy, vocal palsy, acute and chronic laryngitis, leukoplakia and laryngeal edema.

Chronic mucosal irritation by heavy smoking, excessive intake of alcohol and tobacco chewing in Asian countries play significant role in etiology of hoarseness. It was observed that in India and other developing countries the prevailing lower economic status, poorer nutrition, poorer general health, 
different food habits, vocal habits, smoking and drinking habits, unhealthy environment, and different social customs influence the incidence of hoarseness. ${ }^{7}$

\section{Etiology of Hoarseness}

In this study total 26 entities were diagnosed in 251 patients (Table 4). All the cases were examined by Karl Storz videostroboscopy system. Sataloff et al (1991) performed 377 strobovideolaryngoscopy on 352 patients with a structural or neurologic abnormality and 40 entities were diagnosed. ${ }^{18}$ In a study by Woo et al (1991) 195 stroboscopic examinations of larynx were carried out in 146 patients and in hoarse patients 11 different entities were observed. ${ }^{19}$

According to Clark A Rosen (2000) currently there is no standardized nomenclature regarding voice disorder and pathological conditions of the vocal folds. ${ }^{20}$ Brodnitz (I965) states that it is hard to make a distinction between organic and functional factors when deciding the etiology of the voice problem. Some functional factors may accompany an organic voice disorder. Furthermore, a psychological reaction to an organic problem can cause the voice disorder to become more serious than it would normally be. The vocal dysfunction can continue after the organic element has disappeared. ${ }^{21}$

Clark A Rosen (2000) proposed classification and nomenclature, and divided voice disorder into four major categories: $:^{20}$

1. Nonorganic voice disorder (functional): It has a common finding of dysphonia associated with normal vocal fold morphology and motion. It includes muscle tension dysphonia, conversion dysphonia, psychogenic dysphonia and functional dysphonia.

2. Organic voice disorders: It involve actual pathological changes to larynx in general and vocal fold in specific and includes vocal nodules, polyps, cysts, Reinke's edema, granuloma, leukoplakia, carcinoma of vocal fold, etc.

3. Movement disorder: It involves abnormal movement of larynx and caused by abnormalities in muscle control. Common disorders within this category are unilateral vocal fold paralysis, spasmodic dysphonia, etc.

4. Systemic disease: It affect the voice production system. Often systemic diseases have adverse effects on the function of the vocal production tracts and results in a voice change, e.g. reflux laryngitis, infections of larynx and neurological diseases like Parkinson's disease.

Another classification divides voice disorder into two major groups:

1. Functional voice disorders

2. Organic voice disorders.

\section{Functional Voice Disorders}

In present study functional voice disorders (16.33\%) comprised the largest group, associated with a normal vocal fold morphology and movement. It includes muscle tension dysphonia, aphonia, psychogenic dysphonia and falsetto. Batra et al (2004) accounted 51\% of functional voice disorder, which included vocal nodule, polyps and granulomas under functional disorder, since this lesion have been shown to be secondary to vocal abuse/misuse. According to Koufman and Isaacson (1991) functional voice disorders may account for up to $40 \%$ of the cases of dysphonia referred to a multidisciplinary voice clinic. ${ }^{22}$ In present study, we have not included the benign mass lesions secondary to vocal abuse in functional lesion.

\section{Organic Voice Disorders}

Nodule was most common lesion found in $11.95 \%$ cases in present study with $\mathrm{M}: \mathrm{F}$ ratio $1: 1.7$. It was most common pathology found among females (21\%). Vocal nodule was the commonest etiology in study by Parik (1991) with 43.3 and $56.7 \%$ in males and females respectively. ${ }^{7}$ Ghosh et al (2001) found nodule as commonest etiology with incidence of $30 \%$ with male to female ratio $1: 1.5{ }^{10}$ In another study incidence was found only $12.72 \%$ with male to female ratio $1: 1.3 .^{4}$

Second most common pathology was vocal cord palsy (11.16\%). Male predominance was seen with M:F ratio 2.5:1. It was most common pathology found among males (12\%). Some study mentioned it as only 3 and $9 \% .{ }^{4,7,9}$ Male to female ratio was 9:1 in a study. ${ }^{4}$

In our study next common etiology were chronic laryngitis (9.56\%) and malignancy (9.56\%) with equal incidence. In chronic laryngitis male predominance was seen with male to female ratio $3: 1$. In two studies chronic laryngitis was commonest etiology comprising of $48 \%$ in each. ${ }^{4,7}$ Whereas in another studies, it was only 6 and $8 \%$ respectively. ${ }^{9,10}$

In malignancy M:F ratio was 3.8:1. In one study, incidence of malignancy was $14.54 \%$ with male to female ratio as $15: 1{ }^{4}$ In other studies incidence of malignancy was 12,18 , and $8 \%$ respectively. ${ }^{7,9,10}$

Incidence of other major etiological factors in descending order were vocal cyst (5.58\%), edema (5.18\%), acute laryngitis (4.38\%), bowing (3.98\%), vocal polyp (3.59\%), sulcus vocalis (2.79\%) and abductor palsy (2.39\%).

Sataloff (1991) mentioned that strobovideolaryngoscopy is a valuable addition to the diagnostic armamentarium because it allows otolaryngologists to perform a detailed physical examination of the vibratory margins of the vocal fold. The technique has proven helpful in evaluating many patients with voice complaints. This permits diagnosis of structural lesions that are often missed altogether without stroboscopy. ${ }^{18}$ This was also one of the reasons that almost all types of vocal pathologies were diagnosed in this study as compared to other studies where the videostroboscopy was not used.

\section{Management of Hoarseness}

In present study most of the patients were referred for speech therapy and psychotherapy along with vocal conservation and maintenance of vocal hygiene. All the patients were instructed 
for the Do's and Dont's for their respective pathology. Microlaryngeal biopsy and surgery was employed for organic mass lesions, e.g. vocal cyst, polyp. Lesions of infectious origin, e.g. reflux laryngitis, acute and chronic laryngitis and tuberculosis were advised medical therapy along with speech therapy. Cancer patients were referred for radiotherapy. Patients with vocal palsy were advised for complete chest, cardiovascular and neurological evaluation as most of them have underlying pathology. Speech therapy has been given to all unilateral vocal fold paresis and paralysis cases. In many cases, the improvement was sufficient for the patient's needs.

Goals of voice therapy are to maximize vocal efficiency, thereby reducing the vibratory trauma that underlies and exacerbate the masses. ${ }^{23}$ Although therapy alone cannot cure vocal nodules, the surrounding edema may reduce significantly with change in vocal hygiene. Return to near normal function is possible, although some professionals will continue to notice limitations in the voice and thus require surgery. Vocal fold polyps and cysts also should be treated with an initial course of voice therapy to optimize vocal hygiene; however, in these cases, voice therapy less often accomplishes significant recovery of function and surgery is almost always required if associated symptoms are significant. Precise phonomicrosurgical excision of the lesions, with every effort to preserve as much normal tissue as possible, remains the surgery of choice for symptomatic benign lesions. ${ }^{24}$

Treating voice patients requires the interaction of many disciplines. Patients and clinicians alike benefit from a team approach to the patients voice care. Treatment by an interdisciplinary team is important when treating anyone who has a voice disorder and crucial when treating the professional voice users. ${ }^{25}$ The members of team may include a laryngologist, speech-language pathologist, singing voice specialist or psychologist.

Psychologic factors also commonly contribute to voice problems. The voice can be described as an emotional part of each person. Sundberg (1987) described that articulatory and laryngeal structures, and respiratory muscle activity patterns change in relation to 10 different emotions. ${ }^{26}$ This finding indicates an emotional/psychologic connection to the voice. Psychologic factors may be related to the patient's response to the voice disorder and its effect on his or her life. ${ }^{25}$

\section{CONCLUSION}

The incidence of hoarseness was 0.45 and $0.64 \%$ among total OPD and new cases respectively. M:F ratio was 1.89:1 with male predominance. Housewives were the largest group of patients. Around $85.26 \%$ were nonvocal professionals. Functional voice disorder comprised the largest group followed by vocal nodule.

Hoarseness of voice is just a symptom with a very diverse etiology. The etiological data varies in different geographical location and center to center, so every case should be carefully and thoroughly evaluated to know the early diagnosis of underlying pathology for prevention and accurate management.

\section{REFERENCES}

1. Jackson J, Jackson L. Diseases of the Nose, Throat and Ear. Philadelphia: WB Saunders, 1959.

2. Von Leden H. The Clinical Significance of Hoarseness and Related Voice Disorders. Journal Lancet. 1958;78:50-53.

3. Koufman J, Isaacson G (Eds). The spectrum of vocal dysfunction. The Otolaryngologic clinics of North America: Voice disorders. Philadelphia: WB Saunders 1991;47.

4. Sambu Baitha, Raizada RM, Kennedy Singh AK, Puttewar MP, Chaturvedi VN. Clinical profile of Hoarsens of voice. Indian journal of otolaryngology and head and neck surgery 2002 Jan-March;54(1):14-18.

5. Prabhu S Khavasi. Aetiopathological Study of Hoarseness of Voice. A thesis submitted for Mater of Surgery (Otorhinolaryngology) Rajiv Gandhi University of Health Sciences, Bangalore, Karnataka 2005.

6. Mehta AS. An Aetiological Study of hoarseness of voice. A thesis submitted for Master of Surgery (Otorhinolaryngology), Gujarat University, 1985.

7. Nimish Parik. Aetiology study of 100 cases of hoarseness of Voice. Indian Journal of Otolaryngology and Head and Neck surgery. June 91;43(2):71-73.

8. Deshmukh. Clinical study of hoarseness of voice: A thesis submitted for Master of Surgery (Otorhinolaryngology), Gujarat University 1976.

9. Kadambari Batra, Gul Motwani, PC Sagar. Functional voice disorders and their occurrence in 100 patients of hoarseness as seen on fibreoptic laryngoscopy. Indian Journal of Otolaryngology and Head and Neck Surgery. Apr-Jun 2004;56(2):91-95.

10. Swapan K Ghosh, Chattopadhyay S, Bora H, Mukherjee PB. Micro laryngoscopic study of 100 cases of Hoarsens of voice. Indian Journal of otolaryngology and Head and Neck Surgery. Oct-Dec 2001;53(4):270-72.

11. Herrington-Hall BL, Lee L, Stemple JC, Niemi KR, MC Hone MM. Description of laryngeal pathologies by age, sex, and occupation in a treatment-seeking sample. J Speech Hear Disord 1988;53:57-64.

12. Koufman JA. The otolaryngologic manifestations of gastroesopahgeal reflux disease(GERD): A clinical investigation of 225 patients using ambulatory 24-hour $\mathrm{pH}$ monitoring and an experimental investigation of the role of acid and pepsin in the development of laryngeal injury. Laryngoscope 1991;101:1-78.

13. Chopra H, Kapoor M. Study of Benign Glottic lesions undergoing Microlaryngeal surgery. Indian Journal of Otolaryngol and Head and Neck Surgery 1997;49(3):276-79.

14. Fritzell B. Voice disorders and occupations. Log Phon Vocol 1996;21:712.

15. Titze IR, Lemke J, Montequin D. Population in the US work force who rely on voice as a primary tool of trade. A preliminary report. J Voice 1997;11:254.

16. Smith E, Gray S, Dove H, Kirchner L, Heras H. Frequency and effects of teachers' voice problems. Journal of Voice, 11, 1997;81-87.

17. Boominathan P, Rajendran A, Nagarajan R, Jayshree S, Muthukumaran G. Vocal abuse and vocal hygiene practices among different level professional voice users in India: A survey. Asia Pacific Journal of Speech and Hearing 2008;11(1):47-53.

18. Sataloff RT, JR Spiegel, MJ Hawkshaw. "Strobovideolaryngoscopy: Results and clinical value.” Annals of Otology, Rhinology and Laryngology, September 1991;100(9):725-27.

19. Woo P, Colton R, Casper J, Brewer D. Diagnostic value of stroboscopic examination in hoarse patients. Journal of Voice 1991;5(3):231-38. 
20. Clark A Rosen, Thomas Murphy. Nomenclature of voice disorders and vocal pathology. Otolaryngologic clinics of North America. Oct 2000;33(5):923-56.

21. Brodnitz FS. Vocal rehabilitation.A manual prepared for the use of graduates of medicine (4th ed), Rochester MN. Am Acad Ophthalmol Otolaryngol 1971;75.

22. Koufman JA, Isaacson G. The spectrum of vocal dysfunction. Otolaryngol Clin North Am Oct 1991;24(5):985-88.
23. Johns MM. Update on the etiology, diagnosis and treatment of vocal fold nodules, polyps and cysts. Curr Opin Otolaryngol Head-Neck Surg 2003;11:456-61.

24. Franco RA, Andrus JG. Common diagnosis and treatments in professional voice users. Otolaryngol Clin N Am 2007;40:1025-61.

25. Schneider SL, Sataloff RT. Voice therapy for the Professional Voice. Otolaryngol Clin N Am 2007;40:1133-49.

26. Sundberg J. The science of the singing voice. DeKalb (IL): Northern Illinois University Press; 1987;146-56. 